National Climate Assessment Regional Technical Input Report Series
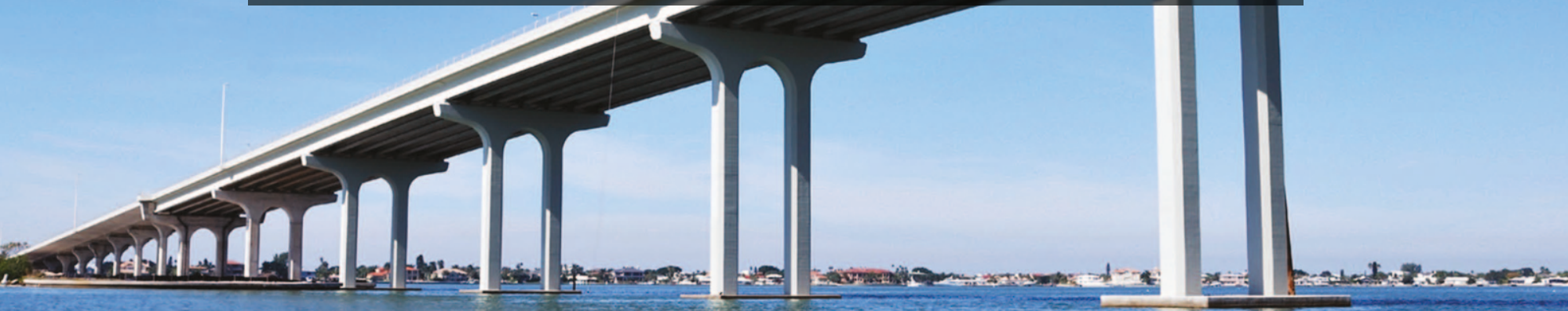

\title{
Climate Change and Infrastructure, Urban Systems, and Vulnerabilities
}

\section{Edited by:}

Thomas J. Wilbanks

Steven J. Fernandez

OisLANDPRESS
Technical Report for the US Department of Energy in Support of the National Climate Assessment
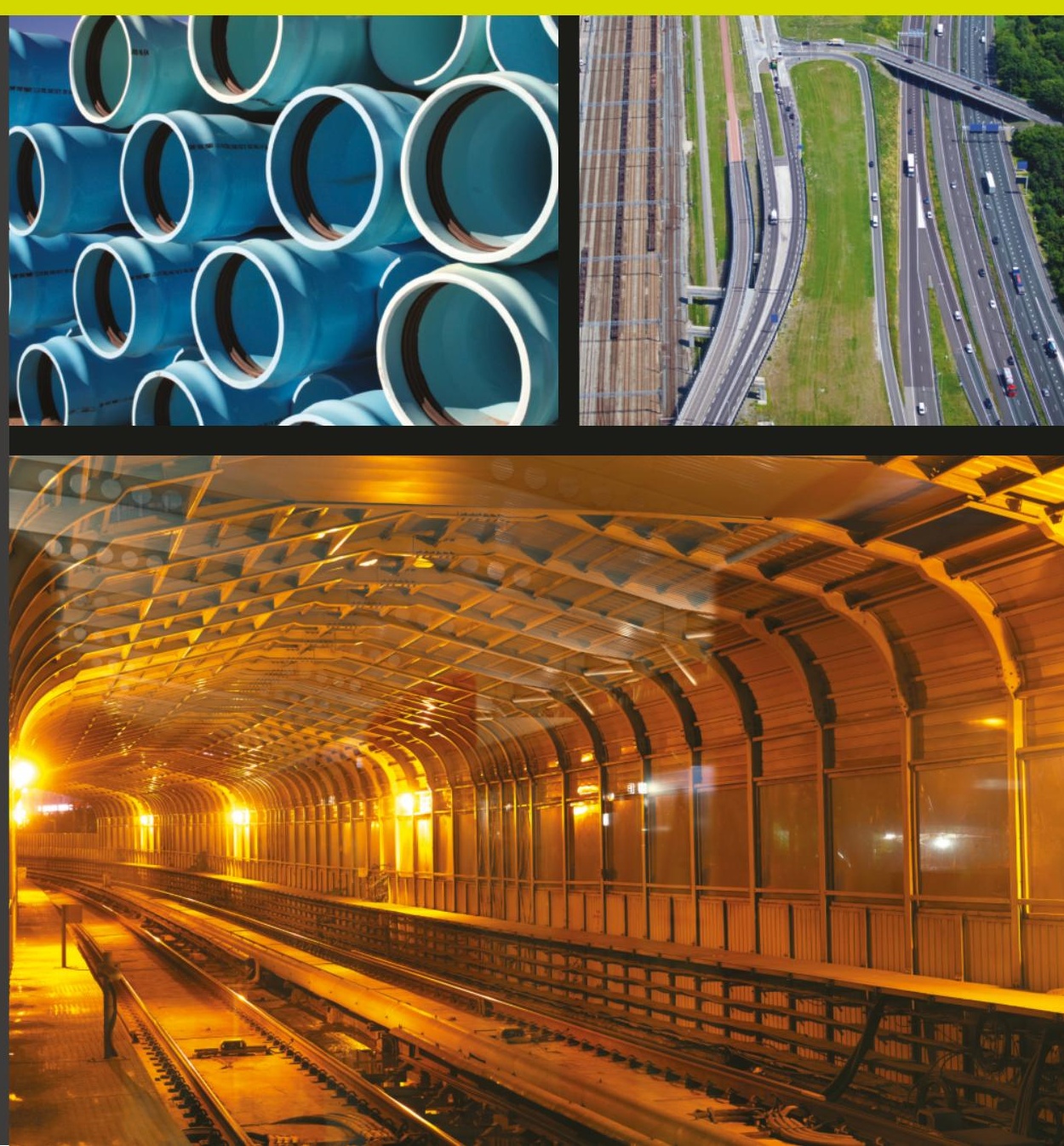

Climate Change and

Infrastructure, Urban

Systems, and Vulnerabilities 



\section{Climate Change and Infrastructure, Urban Systems, and Vulnerabilities}

\section{COORDINATING LEAD AUTHORS}

Thomas J. Wilbanks, ORNL

Steven J. Fernandez, ORNL

\section{LEAD AUTHORS}

George Backus, Sandia National Laboratories Pablo Garcia, Sandia National Laboratories Karl K. Jonietz, LANL

Paul H. Kirshen, University of New Hampshire Michael Savonis, ICF William Solecki, CUNY/Hunter College

Gasper Loren Toole, LANL

\section{CONTRIBUTING AUTHORS}

\section{Melissa R. Allen, ORNL}

Rosina M. Bierbaum, University of Michigan

Theresa J. Brown, Sandia National Laboratories

Nancy E. Brune, Sandia National Laboratories

James L. Buizer, University of Arizona

Joshua Fu, University of Tennessee

Olufemi A. Omitaomu, ORNL

P. Lynn Scarlett, Resources for the Future Megan Susman, EPA

Eric Vugrin, Sandia National Laboratories Sherry B. Wright, ORNL

Rae Zimmerman, NYU

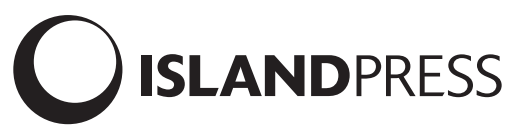

Washington I Covelo | London 
Copyright (@ 2014 U.S. Department of Energy in Support of the National Climate Assessment.

All rights reserved under International and Pan-American Copyright Conventions.

Reproduction of this report by electronic means for personal and noncommercial purposes is permitted as long as proper acknowledgement is included. Users are restricted from photocopying or mechanical reproduction as well as creating derivative works for commercial purposes without the prior written permission of the publisher.

ISLAND PRESS is a trademark of the Center for Resource Economics.

앙 Printed on recycled, acid-free paper

Note: This technical input document in its current form does not represent a Federal document of any kind and should not be interpreted as the position or policy of any Federal, State, Local, or Tribal Government or Non-Governmental entity

Citation: Wilbanks, T., \& Fernandez, S. (Coordinating Lead Authors). (2013). Climate Change and Infrastructure, Urban Systems, and Vulnerabilities: Technical Report for the U.S. Department of Energy in Support of the National Climate Assessment. Washington, DC: Island Press.

To cite specific information, please use the citation at the beginning of each chapter.

Disclaimer: This report was prepared as an account of work sponsored by an agency of the United States Government. Neither the United States Government nor any agency thereof, nor any of their employees makes any warranty, express, or implied, or assumes any legal liability or responsibility for the accuracy, completeness, or usefulness of any information, apparatus, product, or process disclosed or represents that its use would not infringe private owned rights. Reference herein to any specific commercial product, process, or service by trade name, trademark, manufacturer, or otherwise, does not necessarily constitute or imply its endorsement, recommendation, or favoring by the United States Government or any agency thereof. The views and opinions of authors expressed herein do not necessarily state or reflect those of the United States Government or any agency thereof. (Prepared under DOE Contract \# DE-AC05-00OR22725 between Department of Energy Oak Ridge Office and UT-Battelle, LLC)

Manufactured in the United States of America

$\begin{array}{llllllllll}10 & 9 & 8 & 7 & 6 & 5 & 4 & 3 & 2 & 1\end{array}$

Keywords: urban, climate change, vulnerability, infrastructure, sector, sectoral cross-cut, region, energy systems, transportation, water, communication, waste treatment, health-care, drainage, extreme weather, Gulf Coast, hurricanes, Hurricane Katrina, government, Houston, Boston, New York, fire, flood, blackout 



\section{About This Series}

This report is published as one of a series of technical inputs to the Third National Climate Assessment (NCA) report. The NCA is being conducted under the auspices of the Global Change Research Act of 1990, which requires a report to the President and Congress every four years on the status of climate change science and impacts. The NCA informs the nation about already observed changes, the current status of the climate, and anticipated trends for the future. The NCA report process integrates scientific information from multiple sources and sectors to highlight key findings and significant gaps in our knowledge. Findings from the NCA provide input to federal science priorities and are used by U.S. citizens, communities and businesses as they create more sustainable and environmentally sound plans for the nation's future.

In fall of 2011, the NCA requested technical input from a broad range of experts in academia, private industry, state and local governments, non-governmental organizations, professional societies, and impacted communities, with the intent of producing a better informed and more useful report. In particular, the eight NCA regions, as well as the Coastal and the Ocean biogeographical regions, were asked to contribute technical input reports highlighting past climate trends, projected climate change, and impacts to specific sectors in their regions. Each region established its own process for developing this technical input. The lead authors for related chapters in the Third NCA report, which will include a much shorter synthesis of climate change for each region, are using these technical input reports as important source material. By publishing this series of regional technical input reports, Island Press hopes to make this rich collection of information more widely available.

This series includes the following reports:

Climate Change and Pacific Islands: Indicators and Impacts

Coastal Impacts, Adaptation, and Vulnerabilities

Great Plains Regional Technical Input Report

Climate Change in the Midwest: A Synthesis Report for the National Climate Assessment

Climate Change in the Northeast: A Sourcebook

Climate Change in the Northwest: Implications for Landscapes, Waters, and Communities

Oceans and Marine Resources in a Changing Climate

Climate of the Southeast United States: Variability, Change, Impacts, and Vulnerability

Assessment of Climate Change in the Southwest United States

Climate Change and Infrastructure, Urban Systems, and Vulnerabilities

Climate Change and Energy Supply and Use

Electronic copies of all reports can be accessed on the Climate Adaptation Knowledge Exchange (CAKE) website at www.cakex.org/NCAreports. Printed copies are available for sale on the Island Press website at www.islandpress.org/NCAreports. 




\section{Contents}

Preface

List of Figures xiii

List of Tables $\quad$ XV

Executive Summary $\quad x v i i$

\section{CHAPTER 1 INTRODUCTION}

\section{CHAPTER 2 BACKGROUND}

A. The Development Of The Report 3

1) Overview 3

2) Approach 3

3) NCA guidance 3

4) Assessment findings 4

B. The Scope Of The Report 4

1) How "infrastructures" are defined 4

2) How "urban systems" are defined 6

3) Climate change vulnerability and impact concerns for infrastructures 8 and urban systems

4) Climate change adaptation potentials for infrastructure and urban 8 systems

5) Cross-sectoral interactions among infrastructures 8

C. Emerging Contexts For Infrastructure And Urban System Implications Of Climate Change

1) Socioeconomic and land use trends $\quad 15$

2) Sectoral trends and contexts 16

\section{CHAPTER 3 FRAMING CLIMATE CHANGE IMPLICATIONS FOR INFRASTRUCTURES AND URBAN SYSTEM}

A. Sensitivities Of Infrastructures And Urban Systems To Climate Change 17

1) Examples from historical experience 17

2) Sectoral perspectives 18

3) Model integration perspectives $\quad 20$

B. Infrastructure Systems Services 21

C. Linkages Between Infrastructures $\quad 24$

1) Analytical approaches $\quad 24$

2) Factors affecting vulnerabilities, risks, decisions, and $\begin{array}{ll}\text { resilience/adaptability } & 31\end{array}$

3) Insights from critical infrastructure research 34

4) Characteristics of resilient connected infrastructures and 37

D. Assessment Findings 39 


\section{CHAPTER 4 URBAN SYSTEMS AS PLACE-BASED FOCI FOR INFRASTRUCTURE INTERACTIONS}

A. Why The Urban Systems Lens

B. Overviewing Urban Infrastructure Sectors and Services

1) Energy

2) Waste and wastewater

3) Transportation

4) Public health

5) Urban land use and planning

C. Vulnerabilities Associated With Infrastructure Interdependencies

In Urban Systems

D. Infrastructure Interdependencies And Cascading Impacts: A Case Study

1) The study area - current impacts and future events

2) Risk implications

E. Emerging Leadership In Adaptation/Resilience Enhancement

F. Assessment Findings

\section{CHAPTER 5 IMPLICATIONS FOR FUTURE RISK MANAGEMENT STRATEGIES}

A. Overview

1) Philadelphia

2) New York City

3) Other cases 56

B. Two Case Studies - Boston and New York 59

1) City of Boston adaptation planning 59

2) Climate change adaptation in New York City 60

C. Adaptive Infrastructure in Other Countries 63

D. Assessment Findings 68

\section{CHAPTER 6 KNOWLEDGE, UNCERTAINTIES, AND RESEARCH GAPS}
A. The Landscape Of Needs
B. Assessment Findings

\section{CHAPTER 7 DEVELOPING A SELF-SUSTAINED CONTINUING CAPACITY} FOR MONITORING, EVALUATION, AND INFORMING DECISIONS
A. Science Issues
B. Institutional Challenges
C. Assessment Findings 


\section{Preface}

In connection with the U.S. National Climate Assessment scheduled to be completed in 2014, the U.S. Global Change Research Program (USGCRP) and the National Climate Assessment Development and Advisory Committee (NACDAC) invited technical inputs. Many of the most substantive inputs were sponsored by USGCRP agencies, reflecting the knowledge and experience represented by their programs. The technical inputs were due to be submitted by March 1, 2012.

The U.S. Department of Energy (DOE) produced three technical input reports: Climate Change and Infrastructure, Urban Systems, and Vulnerabilities; Climate Change and Energy Supply and Demand; and Climate and Energy-Water-Land system interactions. All three reports were based in part on a major national workshop of experts from a wide variety of communities of knowledge and experience, and all three reports were peer-reviewed. This book provides the content of the first of these reports to a broader audience.

The author team would like to acknowledge the inspiration, leadership, guidance, and support of Bob Vallario, Director of the Integrated Assessment Research Program of DOE's Climate and Environmental Systems Division, Office of Biological and Environmental Research, Office of Science. Without Bob's knowledge and perspectives on everything from the subject areas to the expert communities, the technical input export could not have been produced and delivered on schedule; and he has continued since the report was delivered to put its scientific content to use; not only in the National Climate Assessment but in a wide variety of other program efforts related to DOE's missions. Although he is not listed as an author of this technical report, he is in every way a full partner of the report's authors and their commitments to advance knowledge about the report's topics. 



\section{List of Figures}

Figure 1 Path of Hurricanes Katrina and Rita relative to oil and natural gas production platforms

Figure 2 An illustration of infrastructure interdependencies 10

Figure 3 Infrastructure vulnerabilities to a rapid succession of extreme events 18

Figure 4 Interdependencies: A complex system-of-systems problem 25

Figure 5 An interdependent system of systems approach 25

Figure 6 Infrastructure systems can be modeled as interconnected infrastructure layers

Figure 7 Modeling interdependent urban sectors as each is impacted by climate drivers

Figure 8 Strengths of interdependencies between infrastructures impacted by events and other infrastructures that are disrupted as a result

Figure 9 An illustration of interactions among systems related to climate change impacts

Figure 10 Interdependencies between energy and other sectors

Figure 11 Conceptual illustration of a resilience assessment framework

Figure 12 Curtis and Schneider, 2011, map the vulnerable parts in the study area to 1 meter and 4 meter sea level rise

Figure 13 Historic migration trends into the Miami area (dark) could be reversed in the event of disruptive extreme weather events in Miami (light)

Figure 14 Flooding risks to the New York City area associated with substantial climate change

Figure 15 Adaptive urbanization - climate risk management in cities, flexible adaptation pathways, and interactive mitigation and adaptation 



\section{List of Tables}

Table 1 Impacts on environment, economy, and society

Table 2 Adaptation impacts on environment, economy and society, and mitigation in Boston

Table 3 System interactions - climate change impacts in Boston

Table 4 System Interactions - adaptation in Boston

Table 5 Illustrative depiction of interdependencies among infrastructures in the Miami case depending on infrastructure design features and the location and timing of sector disruptions

Table 6 Movement of population and associated power demand under 1 meter sea level risk scenario

Table 7 City of Boston adaptation actions

Table 8 Climate hazards and coastal flooding events 65

Table 9 Qualitative changes in extreme events 



\section{Executive Summary}

This technical report on "Climate Change and Infrastructure, Urban Systems, and Vulnerabilities" was prepared for the U.S. Department of Energy by the Oak Ridge National Laboratory in support of the U.S. National Climate Assessment (NCA). Prepared on an accelerated schedule to fit time requirements for the NCA, it was a summary of the currently existing knowledge base on its topic, nested within a broader framing of issues and questions that need further attention in the longer run (also see the on-line version of the report, which includes figures in color: http://www.esd.ornl.gov/eess/NCAInfrastructure.shtml).

The report arrived at a number of "assessment findings," each associated with an evaluation of the level of consensus on that issue within the expert community, the volume of evidence available to support that judgment, and the section of the report that provides an explanation for the finding.

Cross-sectoral issues related to infrastructures and urban systems have not received a great deal of attention to date in research literatures in general and climate change assessments in particular. As a result, this technical report breaks new ground as a component of climate change vulnerability and impact assessments in the U.S., which means that some of its assessment findings are rather speculative, more in the nature of propositions for further study than specific conclusions that are offered with a high level of confidence and research support. But it is a start in addressing questions that are of interest to many policymakers and stakeholders.

A central theme of the report is that vulnerabilities and impacts are issues beyond physical infrastructures themselves. The concern is with the value of services provided by infrastructures, where the true consequences of impacts and disruptions involve not only the costs associated with the clean-up, repair, and/or replacement of affected infrastructures but also economic, social, and environmental effects as supply chains are disrupted, economic activities are suspended, and/or social well-being is threatened.

Current knowledge indicates that vulnerability concerns tend to be focused on extreme weather events associated with climate change that can disrupt infrastructure services, often cascading across infrastructures because of extensive interdependencies threatening health and local economies, especially in areas where human populations and economic activities are concentrated in urban areas. Vulnerabilities are especially large where infrastructures are subject to multiple stresses, beyond climate change alone; when they are located in areas vulnerable to extreme weather events; and if climate change is severe rather than moderate. But the report also notes that there are promising approaches for risk management, based on emerging lessons from a number of innovative initiatives in U.S. cities and other countries, involving both structural and non-structural (e.g., operational) options.

More specifically, the report's assessment findings are as follows. In each case, the report includes further information to support the finding.

Regarding implications of climate change for infrastructures in the United States, we find that: 
- Extreme weather events associated with climate change will increase disruptions of infrastructure services in some locations

- A series of less extreme weather events associated with climate change, occurring in rapid succession, or severe weather events associated with other disruptive events may have similar effects.

- Disruptions of services in one infrastructure will almost always result in disruptions in one or more other infrastructures, especially in urban systems, triggering serious cross-sectoral cascading infrastructure system failures in some locations, at least for short periods of time

- These risks are greater for infrastructures that are:

- Located in areas exposed to extreme weather events

- Located at or near particularly climate-sensitive environmental features, such as coastlines, rivers, storm tracks, and vegetation in arid areas

- Already stressed by age and/or by demand levels that exceed what they were designed to deliver

- These risks are significantly greater if climate change is substantial rather than moderate

Regarding implications of climate change for urban systems in the United States, we find that:

- Urban systems are vulnerable to extreme weather events that will become more intense, frequent, and/or longer-lasting with climate change

- Urban systems are vulnerable to climate change impacts on regional infrastructures on which they depend

- Urban systems and services will be affected by disruptions in relatively distant locations due to linkages through national infrastructure networks and the national economy

- Cascading system failures related to infrastructure interdependencies will increase threats to health and local economies in urban areas, especially in locations vulnerable to extreme weather events

- Such effects will be especially problematic for parts of the population that are more vulnerable because of limited coping capacities

Regarding implications of climate change for infrastructure and urban system risk management strategies in the United States, we find that:

- Risks of disruptive impacts of climate change for infrastructures and urban systems can be substantially reduced by developing and implementing appropriate adaptation strategies

- Many of the elements of such strategies can be identified based on existing knowledge

- In most cases, climate-resilient pathways for infrastructure and urban systems will require greater flexibility than has been the general practice, along with 
selective redundancy where particular interdependencies threaten cascading system failures in the event of disruptions

- Revising engineering standards for buildings and other infrastructures to accommodate projected climate change is a promising strategy

- In some cases, especially if climate change is substantial, climate-resilient pathways will require transformational changes, beyond incremental changes.

Regarding implications of climate change for infrastructure and urban system research needs in the United States, we find that:

- Improving knowledge about interdependencies among infrastructures exposed to climate change risks and vulnerabilities will support strategies and actions to reduce vulnerabilities

- The challenge is to recognize that, although uncertainties about climate change and payoffs from specific response strategies are considerable, many actions make sense now, such as developing monitoring systems to support assessments of emerging threats to infrastructures and urban systems

- A high priority should be given to verifying and validating the report's assessment findings, especially where the current evidence is not strong.

Regarding a continuing assessment process for climate change and infrastructure and urban systems in the United States, we find that:

- A self-sustaining long-term assessment process needs a commitment to improving the science base, working toward a vision of where things should be in the longer term

- Capacities for long-term assessments of vulnerabilities, risks, and impacts of climate change on infrastructures and urban systems will benefit from effective partnerships among a wide range of experts and stakeholders, providing value to all partners 
